[Ramsden, I., \& Spoonley, P. (1994). The Cultural Safety Debate in Nursing Education in Aotearoa. New Zealand Annual Review of Education, 3, 161-174]

\section{The Cultural Safety Debate in Nursing Education in Aotearoa}

\author{
IRIHAPETI RAMSDEN AND PAUL SPOONLEY
}

$\mathrm{T}$ he recent debate about cultural safety highlights the distance between those who seek to retain the practices and values of a colonial past, and those who want to proceed to a postcolonial future. In the present case, the latter group have attempted to alter the education of some health professionals, nurses, by offering a critical understanding of colonial structures and their effects, and by providing an alternative that centres on ethnic sensitivity. In most respects, it has been a modest innovation in nursing education in terms of meeting the goal of tino rangatiratanga in health delivery services for iwi. But the opposition that began in 1992 in Metro Magazine and which reached something of a crescendo from mid-1993 illustrates the reluctance of important sectors of the community to even consider such modest changes an improvement. Indeed, the reverse is the case. Cultural safety has become defined as a politically inspired campaign of subversion which represents the agenda of extremism.

Both of us are involved in these changes, one rather more than the other. We have been intrigued by the escalation of the debate and the way in which it has been framed, most notably by editorial staff and some key feature writers in the media. In this paper, we want to briefly rehearse some of the important issues as we see them. In particular, there are four central matters of concern. The first is the role of cultural safety in meeting the requirements of nursing education in the late 1990s and into the twenty-first century. To declare our values, we would want to defend cultural safety as critical to the curriculum for nurses and other health professionals although we would not necessarily defend the way in which it has been taught. The second issue is much broader and concerns the way in which democratic debate and political participation has been circumscribed by the media. In essence, we are highly critical of the way in which the media, with some exceptions, have cast cultural safety as a threat to a set of traditional values. The question is how democratic, accurate and equitable have the media been as the major public forum for this debate? Thirdly, this debate has highlighted the opposition to the self-determination of iwi and the requirement that major institutions such as health and health education should be accountable to Maori. The structures and values of a colonial past are proving to be very difficult to dislodge. Finally, the debate has highlighted the fact that many in the wider community do not understand the work of nurses. Moreover, the professional competence of nurses to develop an appropriate curriculum has been widely questioned by those who have little understanding of the issues and tasks involved.

\section{Cultural Safety And Nursing Education}

In 1990, a report on cultural safety in nursing education was commissioned by the Heads of all but one of the schools of nursing in New Zealand. The report described ways in which cultural safety might be incorporated into nursing education and was the product of wide ranging discussions with Maori, including Maori nurses. The decision had been made by the Nursing Council's Education Committee to require nursing schools to incorporate the obligations of the Treaty of Waitangi into their mission statements and nursing philosophies. The Nursing Council is required by statute to examine the curriculum of every school of nursing and to set and administer the national State examinations for the registration of nurses and midwives. In line with this responsibility, the Nursing Council set a 
requirement that twenty percent of the national examination for Comprehensive Registration should be concerned with cultural safety in 1991. In addition to the requirement that candidates demonstrate that they were academically and clinically competent, and that they were legally and ethically safe, they now had to demonstrate that they were culturally safe. A new term had been added to the nursing lexicon.

In 1992, the Nursing Council commissioned a set of guidelines that would determine the content of cultural safety in curricula throughout the country (see Ramsden,1993). In these guidelines, it was made emphatically clear that Maori did not wish nurses to become ethnologists studying "the habits and customs of the natives" as though they were nineteenth century armchair-based anthropologists. Instead, the objectives of cultural safety in nursing education included:

1. To educate registered nurses and midwives to examine their own cultural realities and the attitudes they bring to each new person they encounter in their practice;

2. To educate registered nurses and midwives to be open minded and flexible in their attitudes toward people from differing cultures to whom they offer and deliver service;

3. To educate registered nurses and midwives not to blame the victims of historical and social processes for their current plight;

4. To produce a workforce of well-educated self-aware nurses and midwives who are culturally safe to practice, as defined by the consumers of the service.

The intent is clear. Cultural safety is firstly an attempt to ensure that consumers have an input into the education of health professionals in order to improve the nursing service. Western women have begun to contest and determine health service delivery as it affects them. The time has come for people of different cultures to do the same. Indigenous peoples have now recovered some control over their own health status to such a point that they have started to question the service delivery offered to them from people of another culture. In New Zealand, the nursing service has been overwhelmingly monocultural and has not met Maori requirements. Cultural safety seeks to remedy this situation and provide a vehicle for minority and indigenous peoples to influence nursing practice.

Therefore cultural safety is an educational process. It involves teaching nurses to recognise themselves as bearers of their own culture and to understand how that culture impacts upon other people. Cultural risk in nursing occurs when people from one culture believe they are demeaned and disempowered by the actions and delivery systems of people from another culture. Cultural safety assumes that all nursing interactions are bicultural regardless of the number of people or the number of cultural frameworks through which messages are filtered between the giver of the message and the receiver of that message. Indeed, invoking multiculturalism is often a way of distracting attention away from the power differences involved and of intr6ducing soft options. Nurses need to understand the critical importance of cultural factors on the effectiveness of health care.

However, an understanding of these cultural influences needs to be combined with an understanding of the economic dimensions of health. Nurses in New Zealand have often confused the cultures of indigenous people with the culture of poverty into which indigenous people had been driven. It follows that cultural safety requires the nurse to be able to have some expertise in understanding the effects of poverty and the various structures and histories which establish and maintain poverty cycles. Nurses, as front line workers in primary health care, require a critical understanding of the effects of poverty on health, and the attempts of indigenous people to re-establish the economic and emotional stability of their own cultural systems as a means of combating such poverty. 
The State Final examinations have sought to test the safety of nurses in terms of a range of factors, of which cultural safety is only one. The questions concern the nursing of people in a range of settings. Interspersed amongst such questions are those which test cross-cultural communication skills. There is no separate cultural safety category as such although the questions which relate to cultural safety constitute twenty per cent of the content of the exams. Those responsible for each nursing course determine the amount of the curriculum which is dedicated to cultural safety.

The philosophy of cultural safety has now become well established although how it is actually taught is a matter of some concern. Nursing educators are able to define how it should be taught and the results vary substantially. For instance, a number have confused cultural safety with Maori studies which has led to significant tensions. One of the recommendations of the report concerning cultural safety was that there should be a six-monthly hui to devise a pedagogy, but this has never happened. Until the public debate, most teachers designed and delivered theirversion of cultural safety according to their skills and personal experience. The debate has been useful to the extent that it has highlighted the need for much greater attention to be paid to the teaching of cultural safety. An important start has been made (see Wood and Schwass, 1993) but more needs to be done to ensure that the pedagogy associated with cultural safety is more carefully thought through and rigorously applied. Effective educational programmes need both a clear curriculum and skilled and committed staff who can implement the programme in a way that makes sense for the various communities they must serve.

\section{Recasting The Debate}

The first major indication that some in the media might find the notion of cultural safety distasteful came from du Chateau (1992) in Metro Magazine. Here, some of the themes and objections were first aired, including certain misconceptions that continue to be repeated. Cultural safety was defined as sensitivity to Maori but not to others. It was seen as "social engineering" driven by a "selfappointed" group and that the "success of the programme will be assessed by that same group of Maoris - who stand to earn considerable amounts of money from it" (ibid, 1992, p. 102). And the question was asked as to whether being medically safe was less important than "politically correct attitudes" (ibid, 1992, p. 97). The next stage came when Anna Penn distributed a sixpage letter to the media, amongst a lot of others, on 7 July 1993 in which she attacked the teaching of cultural safety in the nursing programme at Christchurch Polytechnic. The Christchurch Press ran an initial story on $10 \mathrm{July}$, and this was followed by a number of standard reports along with features from 13 July. Other papers as well as television and radio followed with extensive coverage. In particular, the Dominion took the opportunity to canvass a wide range of issues in what was labelled the "politically correct debate" on its features pages. Cultural safety was a major part of this debate but so too were other issues such as education for Maori. In addition to news reports and features, there were important editorial statements made and a large number of letters were published (72 in the Dominion and 119 in the Press) in the period July to September 1993.

In this developing debate, there were some significant editorial statements that summarised the views of the key media people involved. The focus here is primarily on the Press and the Dominion because they carried more material than any other single paper, radio station or television channel, and because the news and editorial values of these two papers were starkly presented. In the case of the Press, two editorials were offered, the first and more extreme being on 14 July, the second ten days later on 24 July. The first was titled "An instrument of tyranny", and focused on the "absurdities that can result from political correctness and attempts at what is sometimes called 'social engineering' "

Political correctness has become an instrument of tyranny, characterised by bullying, moral blackmail, and the stifling of argument (The Press, 14 July 1993). 
The editorial on 24 July reiterated these themes and stated:

Political correctness is the antithesis of free speech and a democratic society, yet its tentacles reach into the very heart of New Zealand society through government departments, quangos and places of learning (The Press, 24 July 1993).

The Dominion also offered two initial editorials. The first on 27 July questioned whether cultural safety, here redefined as cultural sensitivity, should be examinable, and attacked the "thought police". In the second editorial on 6 August, the language and arguments were more extreme, and cultural safety was seen as having the potential to become "cultural cleansing" while the whole episode had "the hall-marks of another unfortunate experiment" (The Dominion, 6 August 1993). The writer then went on to discuss the "self-righteous aura of the politically correct" and argued for government intervention. As an important postscript, F. Haden, the features editor of the Dominion, made it clear in a column on 22 August that Maoris "have to change, because we are not going to".

A number of themes emerged which were often the subject of one feature article or another and which were picked up in the letters sent to the editor. In particular, the following themes were apparent:

- Members of the majority Pakeha group, and notably Penn, were cast as the victims in the face of an education sector which had "abdicated" to notions of political correctness. What was and remains interesting is the way in which the use of political correctness refers to non-racist or anti-racist educational initiatives but never to the many New Right or conservative positions on education. Further, racism has been redefined here as elsewhere to refer to Pakeha "disadvantage" and the "McCarthyism of Maoris". Notions of who is being racist to whom and who is disadvantaged have been inverted.

- Those advocating these changes were inevitably portrayed as extremist who were and are bent on subverting acceptable and adequate systems. Wetherell and Potter (1992, pp. 150 \&
$155)$ in an analysis of racist discourse in contemporary New Zealand, note that there are well-established means of discrediting protest locally, partly through a certain vocabulary (using labels such as activist, militant, etc.) and partly through a certain logic. They note that many Pakeha use notions of individual rights, rationality and history to "argue for outcomes which we would describe ... as actually "illiberal"" (Wetherell and Potter, 1992, p. 186) and that to define something as compulsory is to define it negatively (ibid, 1992, p. 189). All these elements were present in the reporting and editorial comments offered on those who were said to be responsible for cultural safety.

- The politically-inspired nature of cultural safety was contrasted with what was defined as the politically and culturally neutral curricula of clinical nursing practice. One of the ironies of the debate was that the attempt to open up the cultural values which underpin all nursing practice to critical examination was portrayed as an attempt to undermine critical and open debate. Moreover, there was a sturdy defence of clinical practice as culturally neutral and of the notion that this neutrality is essential for good nursing practice. There was a meeting of the cultural myopia of colonialism and the cultural awareness of post-colonial approaches with little common ground between the two.

- The reasons for cultural safety being considered important by health professionals in the first place was seldom given much attention. The poor health status of Maori and the failure of the health services to address this health status tends to be underplayed in favour of a view that regards anything targeted at Maori as a form of privilege which is unwarranted. The suggestion that racism and/or colonialism might be at fault are dismissed.

In these embedding themes, largely media-defined, certain images and a vocabulary were deployed and the issue was constructed as a major problem. What is interesting is that on a 
number of occasions, the relatively guarded hostility of the media became a much more open antagonism with very hostile language and arguments employed to categorise those associated with cultural safety. The escalation of such antagonism meant that a point was reached very early on when it became impossible to restore a balance to the discussion, certainly as far as features and editorial comment were concerned. News reporting was inclined to be much more neutral. But those interested in alternative readings of the debate would have had to sift through a lot of reporting before they could gain other insights. The Listener (see Ansley, 1993) took a consistently liberal position, and Tremewan (1993) and Frewen (1993) offered critical views of the media's role in the cultural safety debate. An even-handedness was apparent in the Brett (1993) article in North and South while Ranginui Walker (1993) provided important contextual information and a Maori perspective. There were also articles which carried alternative views, and a Dominion reporter such as Sarah Catherall, did not adhere to the highly critical line that marked the editorials or many of the features of her newspaper. But despite this, it was the hostility elsewhere in the Dominion which endures.

The Dominion adopted an interesting editorial position on cultural safety, and one that reflected a fundamental change in the approach the paper adopted to the in-depth material of the features page. The ongoing interest in "political correctness" was used to recast the debate about racial disadvantage and racism. The language used was noticeably more dramatic and inflammatory, the editorial staff adopted a much more politically aggressive posture which condemned liberal positions and the threshold of what constitutes acceptable public comment on racism was expanded (see Gordon \& Rosenberg, 1989). With columnists such as Alan Duff, Craig Bauld and Agnes-Mary Brooke, the attack was focused and unrelenting with a distinct and dismissive vocabulary (e.g., indoctrination, grievance industry, thought police, politically correct, etc.).
The focus here has been on the Dominion and the Press, but the debate was extensively canvassed elsewhere. The imagery of cartoons or the commentary of radio talkback was often offensive while magazines from Metro to New Idea also had their say. It provided a community newspaper with an opportunity to headline its editorial "Tribal Extremism" (Mail, 19 July 1993) and to talk of "ethnic cleansing". On television, the Ralston Group condemned (see Frewen, 1993) and More Issues poked fun.

When such partisan positions are adopted by the media, and in spite of what might be written elsewhere on the same page, questions need to be asked not only about the role of the press in defending a certain position but what such partisanship means for debate and democratic freedom (see Walker, 1990). Given the news and editorial values that have so often driven coverage of this issue, the question becomes one of how well the public understand what constitutes cultural safety. Values will always intrude on the coverage of such an issue, but there is a balance that is required for media coverage to provide a certain level of basic information and which does not seek to portray the parties to this dispute in flattering or unflattering light as the case may be. The inevitable media response is that they are simply covering an issue that their readers, listeners or viewers want to know about and that the way in which they portray the issue is not governed by partisanship. But in attacking the motives and methods of those involved with cultural safety, and in marginalising the reasons for the inclusion of cultural safety, notably the very poor service Maori have received from health services in general, it was inevitable that cultural safety would be cast as the villain in the media dramatisation. This raises important questions about the role of the media in defending traditional and, in this case, Pakeha values against any sort of change which might provide Maori with different and more appropriate services. We would also argue that the freedom of the press inhibits the freedom of speech in important ways.

When the press twists facts, tells lies, declares a cold war on a section of the community, uses editorials as party political 
broadcasts and subjects its readers to a daily breakfast of raw prejudices, it undermines the basic pre-condition of democracy... The freedom of the press then becomes the enemy of the freedom of speech (Parekh, 1988, p. 121).

\section{From Cultural Safety To Equitable Citizenship}

As the debate about cultural safety has moved from the preserve of nursing and health professionals and out into the public domain, it has highlighted the generic issues and obstacles for any form of service delivery which seeks to be culturally sensitive. There are important issues that ought to be debated, including how cultural safety might best be taught in a supportive and productive manner that empowers students, teachers and those working in health. But the episode illustrated here demonstrates the considerable forces that are arrayed against any sort of innovation in the area of cultural sensitivity and in the way that the media in particular have narrowed the debate. It highlights the obstacles to consideration of options that might be postcolonial, that is, structures and practices which try to neutralise the inequities of a colonial past. Cultural safety represents a modest option within such a framework. The reaction highlights the substantial opposition to any move towards tino rangatiratanga, and raises central questions about what is guaranteed by way of citizenship rights in Aotearoa.

Dahrendorf (cited in Riley, 1992, p. 206) has recently argued that the citizenship of a modern state implies certain unambiguous rights, for example, the right to a minimum income or to education. But the combination of a new managerialism and the centrality of the market as the key distributor of goods and services has encouraged certain developments which challenge these notions of citizenship, and therefore challenge the integrity and legitimacy of the modern liberal state. In particular, he cites the growth of "new minorities" who no longer enjoy even the minimal rights of other citizens and who highlight the way in which national frameworks and an assumption of universalism actually disenfranchise these new minorities. He argues instead for a notion of pluralistic citizenship which does not require conformity and is not based on a common civic culture.

The moral basis for such a conception in Aotearoa derives from the Treaty of Waitangi where certain unambiguous social and economic rights are specified. The point is that these have been undermined by the historical process of colonialism, the increasing marginalisation of Maori as a result of events since 1984 and the evolution of neo-racist positions. The process of colonisation has been well-rehearsed and requires little further comment. In the case of increasing marginalisation of Maori, the thrust of iwi to restore their tino rangatiratanga has been gravely affected by the loss of paid employment, the reduction of state services for sectors of the community that relied upon state patronage for certain minimal provisions, and the new cult of individual competitiveness in a market economy. In this context, the nature of Maori impoverishment has been redefined in some cases but in the main, it has been reinforced. In this sense, Maori are disenfranchised and the citizenship rights that are specified in the Treaty of Waitangi become meaningless, at least in many situations.

Neo-racism is part of a major attack on the notion that citizenship implies any rights. In examining the editorial positions apparent in newspapers such as the Dominion, it is clear that the attitudes of those concerned are very traditional. What justifies a label such as neo-racism is the way in which the relatively liberal politics of the 1970s and 1980s on matters concerning minority rights are now being given a new persona. In particular, the citizenship obligations and rights of the Treaty are under major attack, and the arguments of the anti-racist past have been inverted to suggest new victims (Pakeha) and perpetrators (Maori, liberals). The language of the anti-racist is used against Maori while the ambition of incorporating Maori in new forms of management and participatory politics is defined as exclusionary and discriminatory. If there is opposition, then it is deemed to be the result of the efforts of those who would consider such 
initiatives in the first place. To take one of the main articulations of this neo-racism examined here, the print media, it is clear that there has been an escalation in these politics since the late 1980s, and in the language and arguments of those centrally involved. The case of the debate on cultural safety in nursing demonstrates the way in which the threshold of what constitutes acceptable public comment has been noticeably lowered.

\section{References}

Ansley, B. "Anna and the Rednecks", Listener, 14 August, 1993.

Brett, C. "Putting Penn to Paper", North and South, October 1993.

du Chateau, C. "Culture Shock”, Metro Magazine, June, 1992.

Frewen, T. "Media Mythology Builds on Original Myth", National Business Review, 13 August, 1993 .

Gordon, P. and Rosenberg, D. Daily Racism. The Press and Black People in Britain, London: Runnymede Trust, 1989.

McCreanor, T. "Talking About Race", in Yensen, H. et al. (eds), Honouring the Treaty, Auckland: Penguin, 1989.

Ramsden, I. M. Kawa Whakaruruhau: Cultural Safety in Nursing Education in Aotearoa, Wellington, 1991.

Ramsden, I. M. "Cultural Safety", in Manchester, J. and O'Rourke, A. (eds), Liberating Learning: Women as Facilitators of Learning, Wellington, 1993

Riley, D. "Citizenship and the Welfare State”, in Allen, J. Braham, P. and Lewis, P. (eds), Political and Economic Forms of Modernity, Cambridge: Polity/Open University Press, 1992.

Spoonley, P. Racism and Ethnicity (Second Edition), Auckland: Oxford University Press, 1993.

Tremewan, P. "Media Prejudice", City Voice, 26 August, 1993.

Walker, R. "The Role of the Press in Defining Pakeha Perceptions of Maori", in Spoonley, P. and Hirsh, W. (eds), Between the Lines. Racism and the New Zealand Media, Auckland: Heinemann Press, 1990.
Walker, R. "Polemic Without Homework", Metro Magazine, October, 1993.

Wetherell, M. and Potter, J. Mapping the Lanquage of Racism. Discourse and the Legitimation of Exploitation, New York: Harvester Wheatsheaf, 1992.

Wood, P. J. and Schwass, M. "Cultural Safety: A Framework for Changing Attitudes", in Nursing Praxis in New Zealand, 8 (1), 1993, pp. 4-15.

\section{The authors}

Irihapeti Ramsden belongs to the Ngati Irakehu NgaiTahu of Banks Peninsula and Rangitane. Registered as a nurse in the 1960s her concern at poor health service delivery to Maori led to work in anthropology and in changing the education of health professionals so that they examined themselves as culture bearers. Currently she works in education and in the production of health education material which is culture specific to Maori. Her particular interest is in the effects of urbanisation on the retention and adjustments of cultural elements toward sovereignty for Maori.

Associate Professor Paul Spoonley is Associate Dean, Social Sciences, at Massey University's Albany Campus. He is the author or editor of fourteen books, including Racism and Ethnicity (1993) and New Zealand Society (1994). He has recently been involved in Mahi Awatea (Work for Tomorrow) with the Taiwhenua o Heretaunga on unemployment and iwi development. He is currently involved in a project on economic participation in a natural labour market. 